\title{
Vacuum Ultraviolet Spectroscopy and Photochemistry of Zinc Dihydride and Related Molecules in Low-Temperature Matrices
}

\author{
Chris Henchy, Una Kilmartin, and John G. McCaffrey* \\ Department of Chemistry, National University of Ireland Maynooth, Maynooth, Co. Kildare, Ireland \\ Supporting Information
}

ABSTRACT: Optical absorption spectra of thin film samples, formed by the codeposition of zinc vapor with $\mathrm{D}_{2}$ and $\mathrm{CH}_{4}$, have been recorded with synchrotron radiation. With sufficiently low metal vapor flux, samples deposited at $4 \mathrm{~K}$ were found to consist exclusively of isolated zinc atoms for both solids. The atomic absorption bands in the quantum solids $\mathrm{D}_{2}$ and $\mathrm{CH}_{4}$ were found to exhibit large bandwidths, behavior related to the high lattice frequencies of these low mass solids. The reactivity of atomic zinc was promoted with ${ }^{1} \mathrm{P}$ state photolysis leading to the first recording of electronic

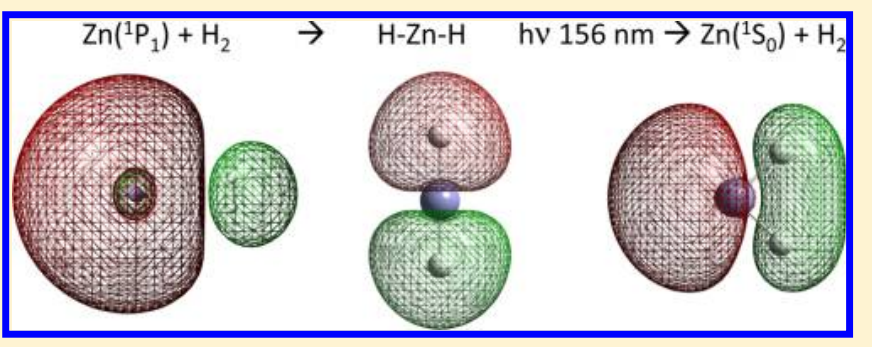
absorption spectra for the molecules $\mathrm{ZnD}_{2}$ and $\mathrm{CH}_{3} \mathrm{ZnH}$ in the vacuum ultraviolet (VUV) region. ${ }^{3} \mathrm{P}$ state luminescence of atomic zinc observed in the $\mathrm{Zn} / \mathrm{CH}_{4}$ system points to the involvement of the spin triplet state in the relaxation of $\mathrm{CH}_{3} \mathrm{ZnH}$ system as it evolves into the $C_{3 v}$ ground state. This state is not involved in the relaxation of the higher symmetry molecule $\mathrm{ZnD}_{2}$. Time dependent density functional theory (TD-DFT) calculations were conducted to predict the electronic transitions of the inserted molecular species. Comparisons with experimental data indicate the predicted transition energies are approximately 0.5 $\mathrm{eV}$ less than the recorded values. Possible reasons for the discrepancy are discussed. The molecular photochemistry of $\mathrm{ZnD}_{2}$ and $\mathrm{CH}_{3} \mathrm{ZnH}$ observed in the VUV was modeled successfully with a simple four-valence electron $\mathrm{AH}_{2}$ Walsh-type diagram.

\section{INTRODUCTION}

Zinc dihydride $\left(\mathrm{ZnH}_{2}\right)$ has been the subject of a number of investigations in recent years. Two primary reasons can be identified for the current interest in this triatomic molecule. The first is that $\mathrm{ZnH}_{2}$ can be considered the parent molecule for the Group 12 metal $\mathrm{M}(\mathrm{ns})^{2}$ dihydrides and considerable interest thereby exists for the determination of its fundamental molecular constants. The second stems from the rich photochemistry of the related dialkyl metals, $\mathrm{MR}_{2}$, such as dimethylzinc. Of particular significance in obtaining precise molecular constants for $\mathrm{ZnH}_{2}$ was the high-resolution mid-IR emission study conducted by Bernath and co-workers. ${ }^{1}$ Analysis of rotationally resolved gas phase spectra for $\mathrm{ZnH}_{2}$ and $\mathrm{ZnD}_{2}$ allowed extraction of the equilibrium bond lengths as 1.52413 and $1.52394 \AA$, respectively, of these two ${ }^{64} \mathrm{Zn}$-containing isotopologues. The band origins of the asymmetric stretching vibrations for ${ }^{64} \mathrm{ZnH}_{2}$ and ${ }^{64} \mathrm{ZnD}_{2}$ were identified at 1889.433 and $1371.631 \mathrm{~cm}^{-1}$, respectively. In addition, verification of the expected linear, centro-symmetric geometry was also achieved. Quite recently, Sebald et al. ${ }^{2}$ have conducted high level ab initio calculations to generate an accurate potential energy function for the ground $\mathrm{X}^{1} \Sigma_{\mathrm{g}}^{+}$electronic state of $\mathrm{ZnH}_{2}$. The coupledcluster method utilized in the theoretical study yielded molecular constants in excellent agreement with Bernath's experimental values for the three hydrogenic isotopologues up to approximately $15000 \mathrm{~cm}^{-1}$ above the equilibrium minimum. Recently microwave absorption spectroscopy ${ }^{3}$ has been used to determine the structure and bonding in methylzinc hydride
$\left(\mathrm{CH}_{3} \mathrm{ZnH}\right)$. The $\mathrm{Zn}-\mathrm{H}$ bond length was determined to be $1.521 \AA$, very similar to that of $\mathrm{ZnH}_{2}$. Consistent with the linear structure of zinc dihydride, the geometry of $\mathrm{CH}_{3} \mathrm{ZnH}$ was found to be $C_{3 v}$.

The vibrational spectroscopy of zinc dihydride has been recorded in a variety of matrix-isolation experiments. Wang and Andrews ${ }^{4}$ generated this species with broadband photolysis of atomic zinc in solid para- $\mathrm{H}_{2}$ (and $\mathrm{H}_{2}$-doped neon) observing the asymmetric stretching mode at $1880.5(1880.6) \mathrm{cm}^{-1}$ and the bending mode at $631.9(632.5) \mathrm{cm}^{-1}$ for ${ }^{64} \mathrm{ZnH}_{2}$. The two other hydrogen isotopologues were also reported in that study, and results were compared with DFT predictions. These modes were reported previously by Andrews ${ }^{5}$ as 1870.8 and 628.3 $\mathrm{cm}^{-1}$ for $\mathrm{ZnH}_{2}$ in argon matrices. Our group ${ }^{6}$ also observed them at this position in Ar but generated with secondary photolysis of dimethylzinc.

Quantum chemical calculations have been used at a variety of levels of sophistication to predict the bond length and vibrational frequencies of ground state zinc dihydride. A comparison with Bernath's experimental values in Table S1 reveals that DFT calculations conducted with the B3LYP functional and the $6-311++\mathrm{G}(3 \mathrm{df}, 3 \mathrm{pd})$ basis set provide results in good agreement with observations. This basis set has been used extensively in the present work, yielding results in

Received: May 13, 2013

Revised: August 23, 2013

Published: August 23, 2013 
complete agreement with the earlier ${ }^{1}$ DFT findings. Thus the ground state equilibrium bond length was found to be 1.5413 $\AA$, and the fundamental vibrational frequencies of $\nu_{1}$, the symmetric $\left(\sigma_{\mathrm{g}}\right)$, and $\nu_{3}$, the asymmetric $\left(\sigma_{\mathrm{u}}\right)$ stretches were 1915.5 and $1926.8 \mathrm{~cm}^{-1}$, respectively, while $\nu_{2}$, the bending $\left(\pi_{\mathrm{u}}\right)$ mode, is predicted at $642.8 \mathrm{~cm}^{-1}$ for ${ }^{64} \mathrm{ZnH}_{2}$. Table S1 in the Supporting Information collects these DFT harmonic data and ${ }^{64} \mathrm{ZnD}_{2}$ results for comparison with a variety of experimental IR findings both in the gas phase and matrices.

Detailed gas phase collisional deactivation studies have been conducted by Breckenridge and co-workers ${ }^{7}$ on the excited triplet $4 \mathrm{p}^{3} \mathrm{P}_{1}$ state of atomic zinc ${ }^{8}$ with pump-probe methods, for molecular hydrogen and its isotopologues, $\mathrm{HD}$ and $\mathrm{D}_{2}$. More recently Umemoto and co-workers 9 have extended this work to the excited singlet $4 \mathrm{p}^{1} \mathrm{P}_{1}$ state. Analysis of the rotational distribution in the zinc hydride product molecule has allowed the inference of a long-lived intermediate in these reactions. This proposal has been examined by Novaro's group $^{10}$ who have determined the reaction paths of excited state atomic zinc with molecular hydrogen. The findings of this theoretical work largely confirm the existence of a deeply bound linear inserted $\mathrm{H}-\mathrm{Zn}-\mathrm{H}$ species, but involving an endothermic reaction with respect to the separated species ground $\left({ }^{1} S_{0}\right)$ state atomic zinc and molecular hydrogen.

In the present contribution we examine the electronic spectroscopy of the zinc dihydrides $\left(\mathrm{ZnD}_{2}\right.$ and $\left.\mathrm{ZnH}_{2}\right)$ as well as methylzinc hydride $\left(\mathrm{CH}_{3} \mathrm{ZnH}\right)$ generated from the reaction of excited ${ }^{1} \mathrm{P}_{1}$ state atomic zinc with $\mathrm{D}_{2} / \mathrm{H}_{2}$ and $\mathrm{CH}_{4}$. This is achieved for atomic zinc isolated in solid matrices formed from the co-condensation of zinc vapor with molecular deuterium $\left(\mathrm{D}_{2}\right)$, methane $\left(\mathrm{CH}_{4}\right)$, and $\mathrm{H}_{2}$ in doped $\mathrm{Ar}$ matrices. Any luminescence detected in the current reactive host solids as a result of zinc ${ }^{1} \mathrm{P}_{1}$ photoexcitation is compared with that previously observed by our group for atomic zinc isolated in inert solids such as neon ${ }^{11}$ and argon ${ }^{12}$ matrices. The electronic spectra of the resulting "inserted" species have been recorded for the first time in the vacuum-UV range. Furthermore, repeated scans in the VUV region have revealed photodissociation of the inserted molecular species regenerating atomic zinc. Time-dependent density function theory (TDDFT) calculations were then used to analyze the nature of the electronic transitions responsible for the absorption spectra of the inserted molecules. This method was also used to examine the efficient photodissociation observed for these species in the VUV.

\section{METHODS}

A. Experimental Section. Absorption spectra in the vacuum ultraviolet (VUV) region were recorded using synchrotron radiation with the HIGITI setup on the W3.1 beamline at HASYLAB, DESY, Hamburg, Germany. Scans in the $120-350 \mathrm{~nm}$ range were done with an $\mathrm{LiF}$ filter in the primary monochromator-a modified $1.0 \mathrm{~m}$ Wadsworth-to preclude short wavelength light reaching the sample via high order transmittance. A sodium-salicylate converter was used with an XP2020 photomultiplier tube (PMT) for light detection in the VUV. Emission spectra in this region were recorded with a $0.4 \mathrm{~m}$ Seya-Namioka vacuum monochromator using a Hamamatsu (model 1645U-09) multichannel plate for photon detection. A liquid nitrogen-cooled, charged coupled device (CCD) detector (Princeton Instruments, model LN/ CCD 1108PB) was used to record emission spectra in the UVvisible region. This steady-state CCD camera was mounted on a $0.25 \mathrm{~m}$ Spex $240 \mathrm{M}$ imaging monochromator which was coupled by a $2 \mathrm{~m}$ optical fiber to the sample. The CCD chip consists of $1100 \times 330$ pixels and was operated at $-100{ }^{\circ} \mathrm{C}$ with exposure times typically of $5 \mathrm{~min}$.

Samples were made by the codeposition of zinc vapor with a large excess of the host gas (deuterium or methane) onto an $\mathrm{LiF}$ window at $4 \mathrm{~K}$. This was the minimum temperature attainable on the sample holder, with the Leybold-Heraeus flow-through liquid helium cryostat used. All of the host materials used in the present study, $\mathrm{Ne}, \mathrm{Ar}, \mathrm{D}_{2}, \mathrm{H}_{2}$, and $\mathrm{CH}_{4}$, are transparent in the wavelength range of interest with the exception of $\mathrm{CH}_{4}$, which starts to absorb for $\lambda<145 \mathrm{~nm}$. Zinc vapor was produced by electron bombardment of a $2.0 \mathrm{~mm} \mathrm{Zn}$ rod placed in a molybdenum holder. Full details of the electron bombardment metal atom source used have been presented elsewhere. ${ }^{13}$ In contrast to solid $\mathrm{D}_{2}$, none of the attempts made at $4 \mathrm{~K}$ to isolate zinc atoms in neat, solid hydrogen were successful. However, Ar samples containing up to $10 \% \mathrm{H}_{2}$ were found to be stable even when deposited at $12 \mathrm{~K} . \mathrm{Zn} / \mathrm{H}_{2}$ photochemistry was analyzed in these $\mathrm{H}_{2}$-doped Ar matrices.

B. Calculations. The DFT calculations conducted in this study all used the B3LYP functional and were performed with the Gaussian-03 suite of programs ${ }^{14}$ running on a Linux workstation, which has been described ${ }^{15}$ in our earlier work. In the present study the $6-311++\mathrm{G}(3 \mathrm{df}, 3 \mathrm{pd})$ basis set was used exclusively. As indicated in Table 1 , this method yielded an optimized geometry and vibrational frequencies of $\mathrm{ZnH}_{2}$ identical to the values previously published in Table S13 of the supplementary data of ref 1 . Moreover, the DFT predictions obtained for $\mathrm{CH}_{3} \mathrm{ZnH}$ also agreed with earlier DFT, ${ }^{16}$ microwave, $^{3}$ and matrix results ${ }^{5}$ as listed in Table S1 of the Supporting Information (SI).

Table 1. A Comparison of the Structural and Vibrational Data of $\mathrm{CH}_{3}-\mathrm{Zn}-\mathrm{H}$ Predicted by the Current DFT Calculations and Determined in Previous Experimental Studies $^{a}$

$\begin{array}{lcc} & \text { DFT/B3LYP } & \text { experimental results } \\ & \text { Bond Length }(\AA) & \\ \mathrm{Zn}-\mathrm{H} & 1.5425 & 1.521 \\ \mathrm{Zn}-\mathrm{C} & 1.9546 & 1.928 \\ \mathrm{C}-\mathrm{H} & 1.0912 & 1.14 \\ & \text { Bond Angle (deg) } \\ \mathrm{Zn}-\mathrm{C}-\mathrm{H} & 110.9 & 110.2 \\ \mathrm{H}-\mathrm{C}-\mathrm{H} & 107.9 & \\ \mathrm{H}-\mathrm{Zn}-\mathrm{C} & 180.0 & 180.0 \\ & \text { Frequencies }\left(\mathrm{cm}^{-1}\right), \mathrm{A}_{1} \text { modes } \\ \mathrm{C}-\mathrm{H} \text { s str } & 3021.1 & 2920 \\ \mathrm{H}-\mathrm{Zn} \text { str } & 1902.7 & 1866 \\ \mathrm{CH} \text { s bend } & 1208.4 & 1179 \\ \mathrm{C}-\mathrm{Zn} \text { str } & 552.3 & 564 \\ & \\ \mathrm{C}-\mathrm{H} \text { as.str } & \text { Frequencies }\left(\mathrm{cm}^{-1}\right), \mathrm{E} \text { modes } \\ \mathrm{CH} \text { as bend } & 3094.2 & \\ \mathrm{CH} \mathrm{H}_{3} \text { rock } & 1456.4 & 687 \\ \mathrm{C}-\mathrm{Zn}-\mathrm{H} \text { bend } & 702.9 & 443 \\ & 422.9\end{array}$

${ }^{a}$ The structural experimental data are from gas phase microwave spectra presented in ref 3 , while the vibrational data are from matrix results presented in ref 5 . The DFT vibrational frequencies quoted are harmonic values. All of the vibrational frequencies listed are in wavenumber $\left(\mathrm{cm}^{-1}\right)$ units, while the bond lengths are in Angstrom units. 
Excited state calculations on $\mathrm{ZnH}_{2}\left(\mathrm{CH}_{3} \mathrm{ZnH}\right)$ were carried out with the TD-DFT method using the optimized geometry of the $D_{\infty h}\left(C_{3 v}\right)$ ground state molecule. Once calculations had converged, the excitation energies, oscillator strengths $(f)$, and transition dipole moments of the first 50 excited states were extracted. The energies of the molecular orbitals were obtained using the "pop=reg" command, yielding values for all 16 occupied and 101 virtual orbitals of $\mathrm{ZnH}_{2}$. Excited state calculations on methylzinc hydride $\left(\mathrm{CH}_{3} \mathrm{ZnH}\right)$ were conducted in a similar fashion but in this case involving 20 occupied and 172 virtual orbitals. The molecular orbital energies were also determined as a function of angle between the linear and bent $\left(90^{\circ}\right)$ geometries. By doing these calculations in $5^{\circ}$ increments, so-called "Walsh" diagrams were thereby produced. The MO plots shown in these diagrams were produced from the electronic density. This was done in Gaussian 03 by generating a "cube" file for a given molecular orbital. The electronic density was then plotted as a wireframe over the molecule showing the shape and parity of the orbitals of interest.

\section{RESULTS}

A. Deposition. An absorption spectrum recorded in the VUV-UV region for a $\mathrm{Zn} / \mathrm{D}_{2}$ sample formed with low metal loading is shown by the top trace in Figure 1. Only a single, albeit structured, band is present whose center feature is located at $209.6 \mathrm{~nm}$. Due to the sparsity of electronic transitions of atomic zinc in the wavelength range longer than $200 \mathrm{~nm}$, this 3fold split absorption band can immediately be assigned to the resonance $4 \mathrm{p}^{1} \mathrm{P}_{1} \leftarrow 4 \mathrm{~s}{ }^{1} \mathrm{~S}_{0}$ transition. As indicated by the

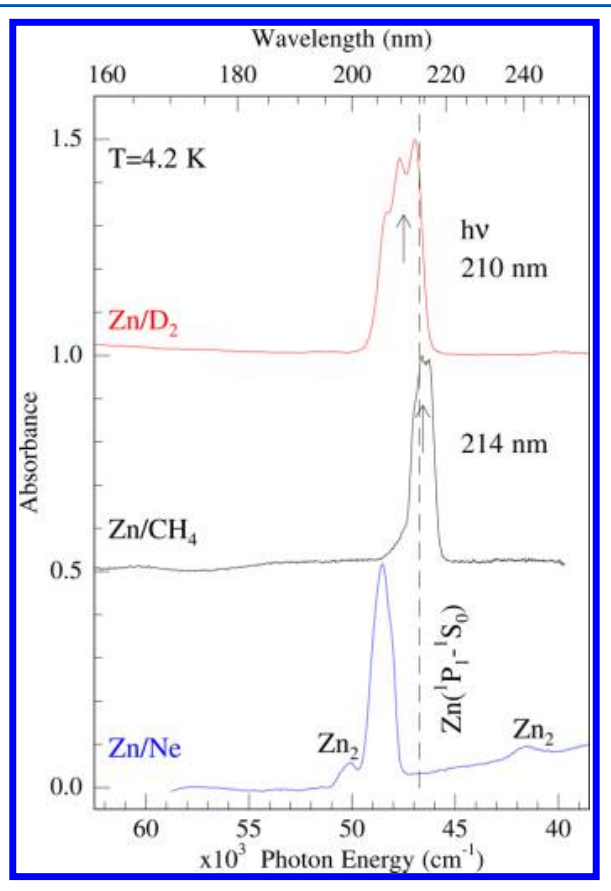

Figure 1. Absorption spectra recorded for $\mathrm{Zn}$ isolated in the molecular matrices $\mathrm{D}_{2}$ and $\mathrm{CH}_{4}$ deposited at 4 and $12 \mathrm{~K}$, respectively, both of which were scanned at $4.2 \mathrm{~K}$. The location of the resonance $4 \mathrm{p}^{1} \mathrm{P}_{1} \leftarrow$ $4 \mathrm{~s}{ }^{1} S_{0}$ transition of atomic zinc in the gas phase $(213.9 \mathrm{~nm})$ is indicated by the dashed vertical line. As indicated in the figure, a blue shift of the entire band occurs for $\mathrm{Zn} / \mathrm{D}_{2}$ from the gas phase position, but a red shift exists in $\mathrm{Zn} / \mathrm{CH}_{4}$. For comparison the absorption spectrum of $\mathrm{Zn} / \mathrm{Ne}$ is presented on the bottom revealing a less resolved main band and features recently attributed (ref 11) to zinc dimer. dashed vertical line in Figure 1, a blue shift of the band occurs from the $213.9 \mathrm{~nm}$ gas phase position ${ }^{17}$ of the atomic transition. Two other major characteristics of the atomic absorption profile recorded in solid $\mathrm{D}_{2}$ are the large bandwidth $\left(\sim 2050 \mathrm{~cm}^{-1}\right)$ and the pronounced 3-fold splitting with resolved peaks at 206.4, 209.6, and $213.1 \mathrm{~nm}$.

Shown by the middle trace in Figure 1 is the absorption spectrum recorded for zinc isolated in a pure methane matrix $\left(\mathrm{Zn} / \mathrm{CH}_{4}\right)$. In contrast to the deuterium sample, the absorption band is now centered slightly to the red of the gas phase transition and is considerably narrower. However, it also exhibits characteristic 3-fold splitting, with partially resolved features at 212.6, 214.5, and $216.5 \mathrm{~nm}$. For comparison purposes, the absorption spectrum of atomic zinc isolated in solid neon ${ }^{11}$ is shown by the bottom trace in Figure 1. While the atomic band in neon is located blue of the gas phase transition-roughly in the same region as $\mathrm{Zn} / \mathrm{D}_{2}-3$-fold splitting is not evident and additional bands due to $\mathrm{Zn}$ dimer are now present at the indicated positions. The existence of pronounced dimer bands in neon samples reveals more efficient isolation of zinc atoms in solid deuterium and methane matrices than in neon. This difference will be discussed in more detail ahead in relation to possible site occupancies.

Lineshape analyses done on the absorption bands of the $\mathrm{Zn}$ / $\mathrm{D}_{2}, \mathrm{Zn} / \mathrm{CH}_{4}$, and $\mathrm{Zn} / \mathrm{Ar}$ systems are presented together in Figure $S 1$ of the Supporting Information. In the Gaussian fits shown in Figure $S 1$ three components, all with the same line width, were used on a given system. With the exception of $\mathrm{Zn}$ / $\mathrm{CH}_{4}$, where a minor blue site exits, the use of only three components provides a good description of the recorded bands. The same fitting procedure was successful for all of the systems, the details of which are collected in Table 2 . This indicates that similar 3-fold splitting of the $4 \mathrm{p}^{1} \mathrm{P}_{1} \leftarrow 4 \mathrm{~s}^{1} \mathrm{~S}_{0}$ electronic transition occurs in the three hosts. As the $\mathrm{Zn} / \mathrm{Ne}$ absorption and excitation spectra have recently been analyzed ${ }^{11}$ in detail, only the relevant aspects will be compared with the present data. The fits done on $\mathrm{Zn} / \mathrm{Ne}$ utilized different parameters, ${ }^{11}$ including variable linewidths and the requirement of a fourth

Table 2. Absorption Band Positions Recorded for the $4 p$ ${ }^{1} P_{1}-4{ }^{1} S_{0}$ Transition of Atomic Zinc Isolated in the Solids Formed from the Light Materials Deuterium, Methane, Neon, and Argon at $4.2 \mathrm{~K}^{a}$

$\begin{array}{cccc}\mathrm{Zn} & \text { absorption center }(\mathrm{nm}) & \text { absorption energy }\left(\mathrm{cm}^{-1}\right) & \Delta\left(\mathrm{cm}^{-1}\right) \\ \mathrm{D}_{2} & 206.4 & 48444 & 742 \\ & 209.6 & 47700 & 742 \\ & 213.1 & 46992 & 742 \\ \mathrm{CH}_{4} & 212.6 & 47025 & 435 \\ & 214.5 & 46614 & 435 \\ & 216.5 & 46191 & 435 \\ \mathrm{Ne} & 203.68 & 49095 & 600 \\ & 205.17 & 48740 & 561 \\ & 206.15 & 48509 & 375 \\ \mathrm{Ar} & 205.15 & 48747 & 412 \\ & 206.75 & 48367 & 412 \\ & 208.47 & 47967 & 412\end{array}$

${ }^{a}$ The gas phase position ${ }^{17}$ of this transition is at $46745.413 \mathrm{~cm}^{-1}$. All of the matrix energies quoted are in wavenumber $\left(\mathrm{cm}^{-1}\right)$ units. The bandwidths $(\Delta$, fwhm $)$ quoted for the matrix features were extracted in the Gaussian lineshape fits of the spectra presented in Figure S1.

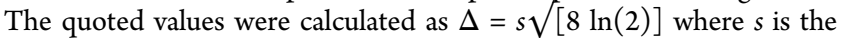
variance in the fitted function, $G(x)=a \exp \left[-(x-m)^{2} /\left(2 s^{2}\right)\right]$. 
component. This contrasting behavior points to different site occupancy in solid neon compared with the molecular hosts studied in the present work and the earlier ${ }^{12} \mathrm{Ar}$ data.

B. Luminescence. No emission was observed for $\mathrm{Zn} / \mathrm{D}_{2}$ samples either in the UV or in the visible spectral regions with excitation into the atomic resonance absorption band shown in Figure 1. This situation is depicted in the central panel of Figure 2 with excitation at $210 \mathrm{~nm}$. It is in stark contrast to

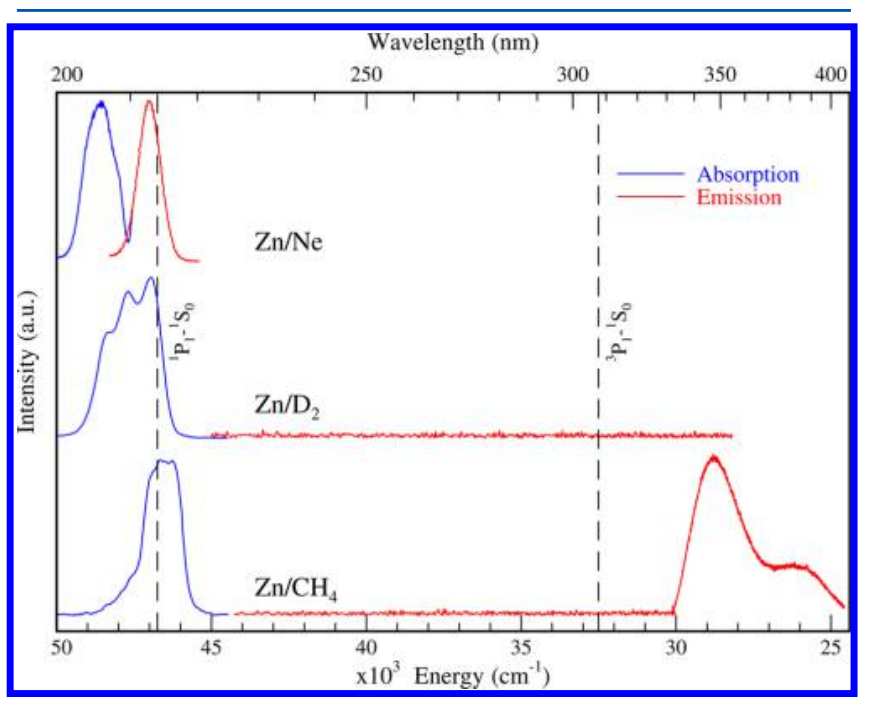

Figure 2. A summary of the emission spectra recorded at $4.2 \mathrm{~K}$ in the $\mathrm{Zn} / \mathrm{D}_{2}$ and $\mathrm{Zn} / \mathrm{CH}_{4}$ systems. As indicated by the middle trace, no emission exists in the $\mathrm{Zn} / \mathrm{D}_{2}$ system, while only the spin triplet is present (bottom trace) for $\mathrm{Zn} / \mathrm{CH}_{4}$. It is located at the red-shift of the atomic zinc $4 \mathrm{p}^{13} \mathrm{P}_{1}-4{ }^{1} \mathrm{~S}_{0}$ transition which occurs in the gas phase at approximately $308 \mathrm{~nm}$. For comparison the emission recorded in $\mathrm{Zn} /$ $\mathrm{Ne}$ is shown in which singlet state atomic emission is observed.

atomic zinc isolated in the solid methane where, as shown in the bottom panel, singlet excitation at $214 \mathrm{~nm}$ produces emission at $348 \mathrm{~nm}$ and a red shoulder at $380 \mathrm{~nm}$. From the long-lived nature ${ }^{18}$ of this near-UV emission, these bands can be attributed to the atomic $\mathrm{Zn} 4 \mathrm{p}^{3} \mathrm{P}_{1}$ state which occurs in the gas phase ${ }^{17}$ at $307.68 \mathrm{~nm}$.

Comparable excitation at $205.4 \mathrm{~nm}$ in $\mathrm{Zn} / \mathrm{Ne}$ produces ${ }^{11}$ intense emission at $212.8 \mathrm{~nm}$ as shown in the top trace of Figure 2. With a radiative lifetime of $1.16 \mathrm{~ns}$ and its spectral location, these characteristics indicate that this emission can be assigned to the fully allowed $4 \mathrm{p}^{1} \mathrm{P}_{1} \rightarrow 4 \mathrm{~s}{ }^{1} \mathrm{~S}_{0}$ transition. Thus, singlet P-state fluorescence dominates in neon, ${ }^{11}$ as it does in argon and krypton matrices. ${ }^{12}$ In light of the data presented in Figure 2, it is thereby evident that singlet fluorescence of atomic zinc is completely quenched in both solid $\mathrm{D}_{2}$ and $\mathrm{CH}_{4}$. In the latter system, the atomic triplet state is however produced with high efficiency, a situation observed previously in $\mathrm{Zn} / \mathrm{Xe}$.

C. Atomic Photolysis. The reactivity of excited $4 \mathrm{p}^{1} \mathrm{P}_{1}$ state atomic zinc in solid deuterium was monitored in the VUV upon photolysis at $210 \mathrm{~nm}$, a wavelength indicated by the upper arrow in Figure 1. The result of a $15 \mathrm{~min}$ irradiation is presented as a "difference" absorption spectrum in the top trace of Figure 3. In this spectrum depletion of the 3-fold-split atomic resonance band centered at $210 \mathrm{~nm}$ is very evident, but more significantly, this depletion is accompanied by the appearance of a pair of broad, featureless bands at 145 and $155 \mathrm{~nm}$ as well as the hint of a much weaker band at $168 \mathrm{~nm}$.

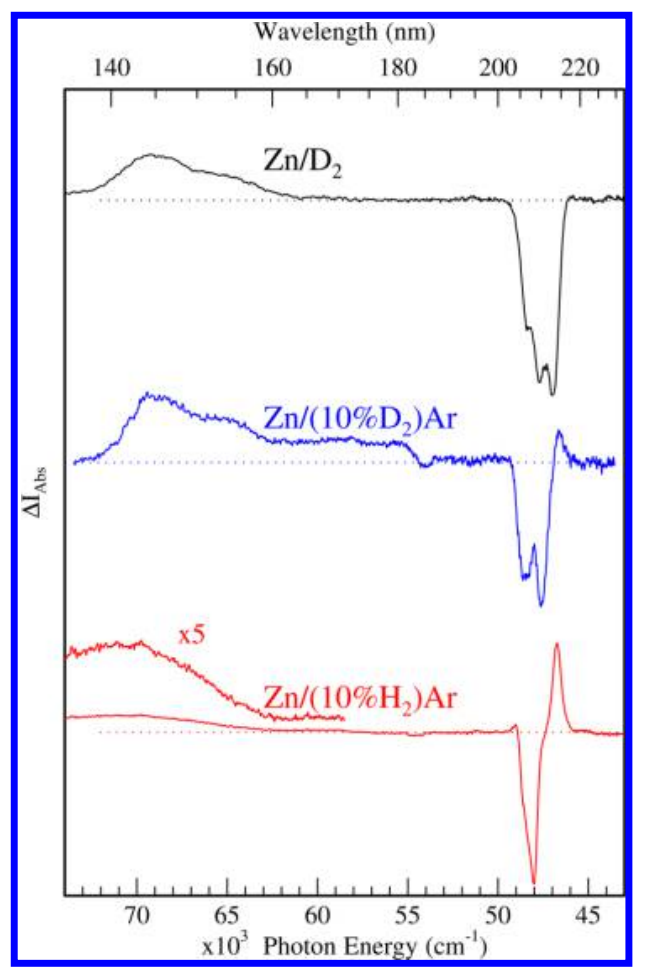

Figure 3. Changes observed in the VUV-UV absorption spectra of the $\mathrm{Zn} / \mathrm{D}_{2}$ system upon atomic photolysis at specific wavelengths (indicated by the arrows in Figure 1) shown as difference spectra. The negative peaks in the plots indicate the loss of the atomic bands, while the positive ones reveal the growth of transitions in the VUV. In addition to the pure $\mathrm{D}_{2}$ matrix result, the response of a $10 \% \mathrm{D}_{2}$ in $\mathrm{Ar}$ sample and a $10 \% \mathrm{H}_{2}$ in Ar sample to similar irradiation are shown in the lower panel. The dip evident at approximately $185 \mathrm{~nm}$ in the $10 \%$ $\mathrm{D}_{2}$ in $\mathrm{Ar}$ sample arose due to a change in the SR beam position during the scan and is not of photochemical significance.

Because of the absence of samples composed of atomic zinc isolated in neat $\mathrm{H}_{2}$ matrices, the photochemical activity of zinc with hydrogen was examined in Ar samples containing $10 \% \mathrm{H}_{2}$ $\left(\mathrm{Zn} / \mathrm{H}_{2} \mathrm{Ar}\right)$. To allow direct comparison with the results obtained for the pure $\mathrm{Zn} / \mathrm{D}_{2}$ system, $\mathrm{D}_{2}$-doped $\mathrm{Ar}$ samples of composition similar to $\mathrm{H}_{2} \mathrm{Ar}$ were also produced. The effect of atomic zinc photolysis in a $\mathrm{Zn} / \mathrm{D}_{2} \mathrm{Ar}$ sample is shown in the middle trace of Figure 3. As observed with pure $\mathrm{D}_{2}$ samples (upper trace), new absorption bands are produced in the 140$160 \mathrm{~nm}$ region, but the changes produced in the atomic absorption in the doped $\mathrm{D}_{2} / \mathrm{Ar}$ samples are more complex. In particular, an increase is observed in one feature located at 215 $\mathrm{nm}$ which is due to photolytically induced site interconversion, that is, the isolation of the zinc atom in a new site in the $\mathrm{D}_{2}$ doped Ar sample. A similar, but more pronounced, effect is evident in the difference spectrum recorded for a $\mathrm{Zn} / 10 \% \mathrm{H}_{2} \mathrm{Ar}$ sample, shown in the bottom trace in Figure 3. This effect arises from ill-defined sites of isolation of atomic zinc in the lessstructured doped-Ar samples. Clearly the VUV absorptions of $\mathrm{Zn} / 10 \% \mathrm{H}_{2} \mathrm{Ar}$ occur in the same spectral region but are less structured than in the corresponding $\mathrm{D}_{2}$-doped Ar samples. It is also evident that the amount of photochemical product generated in the $\mathrm{H}_{2}$-doped $\mathrm{Ar}$ samples is less than in the equivalent $\mathrm{D}_{2}$-doped $\mathrm{Ar}$ samples. This is probably related to the less efficient trapping of the lighter isotopologue in Ar.

Excited state reactivity of zinc with methane was examined with photolysis at $214 \mathrm{~nm}$ whose location is shown by the 
arrow in the middle panel of Figure 1 . The result of a $15 \mathrm{~min}$ irradiation at this wavelength is presented as a "difference" absorption spectrum in the upper trace of Figure 4. In this

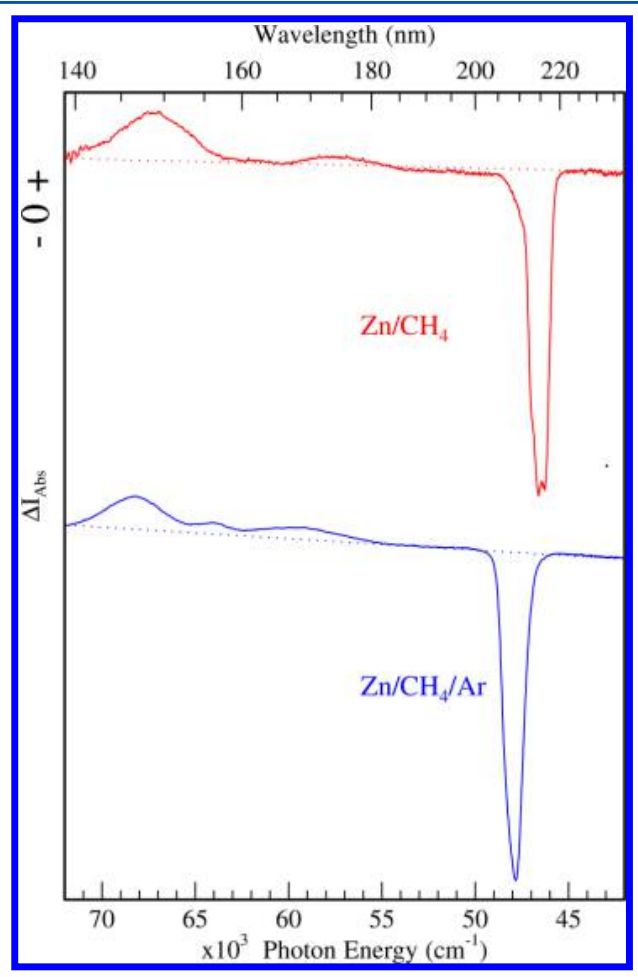

Figure 4. Same as for Figure 3 except for the $\mathrm{Zn} / \mathrm{CH}_{4}$ system. The lower trace shows the results obtained for a 5\% methane in the $\mathrm{Ar}$ sample.

spectrum depletion of the atomic resonance band is evident as well as the appearance of at least three featureless bands at 174, 162 , and $149 \mathrm{~nm}$. These bands are all in the vacuum-UV but at lower energy than those observed in $\mathrm{Zn} / \mathrm{D}_{2}$. The noise evident at wavelengths shorter than $145 \mathrm{~nm}$ in the $\mathrm{Zn} / \mathrm{CH}_{4}$ spectrum is due to the strong absorption of the host material, methane, in this region.

The reactivity of excited state atomic zinc with methane was also examined in $\mathrm{CH}_{4}$ doped-Ar matrices. The "difference" absorption spectrum shown by the bottom trace in Figure 4 presents the results of a $15 \mathrm{~min}$ irradiation at $208 \mathrm{~nm}$. In this $5 \% \mathrm{CH}_{4} / \mathrm{Ar}$ sample, depletion of the atomic resonance band is much simpler than what is observed in the $\mathrm{H}_{2}$-doped $\mathrm{Ar}$ samples with clean loss of the atomic features, that is, free from site interconversion. The appearance of at least three featureless bands in the VUV is also evident in the figure with a better $\mathrm{S} / \mathrm{N}$ ratio than obtained in the pure methane sample. However, as shown by the gray trace in the upper panel of Figure S2, the three new bands in Ar are all to the blue of the three bands in pure methane (black trace). The locations of the bands in doped- $\mathrm{CH}_{4}$ Ar samples are 168, 156, and $146.5 \mathrm{~nm}$ compared with 174,162 , and $149 \mathrm{~nm}$ in neat $\mathrm{CH}_{4}$. In contrast, the bottom panel of Figure S2 reveals that little or no shift occurs in the bands observed in the $\mathrm{Zn} / \mathrm{D}_{2}$ system in pure deuterium (red trace) and $\mathrm{D}_{2}$-doped Ar matrices (gray trace). The contrasting behavior of the VUV bands of $\mathrm{ZnD}_{2}$ and $\mathrm{CH}_{3} \mathrm{ZnH}$ in Ar may be related to site occupancy whereby the latter is cramped in a divacancy, while the former fits easily into such a site.

D. VUV Photolysis. Both of the strong vacuum-UV bands in the $\mathrm{Zn} / \mathrm{D}_{2}$ system were found to be very sensitive to photolysis. As indicated in the two lower traces in Figure 5, irradiation at 145 and $153 \mathrm{~nm}$ into each excited molecular band

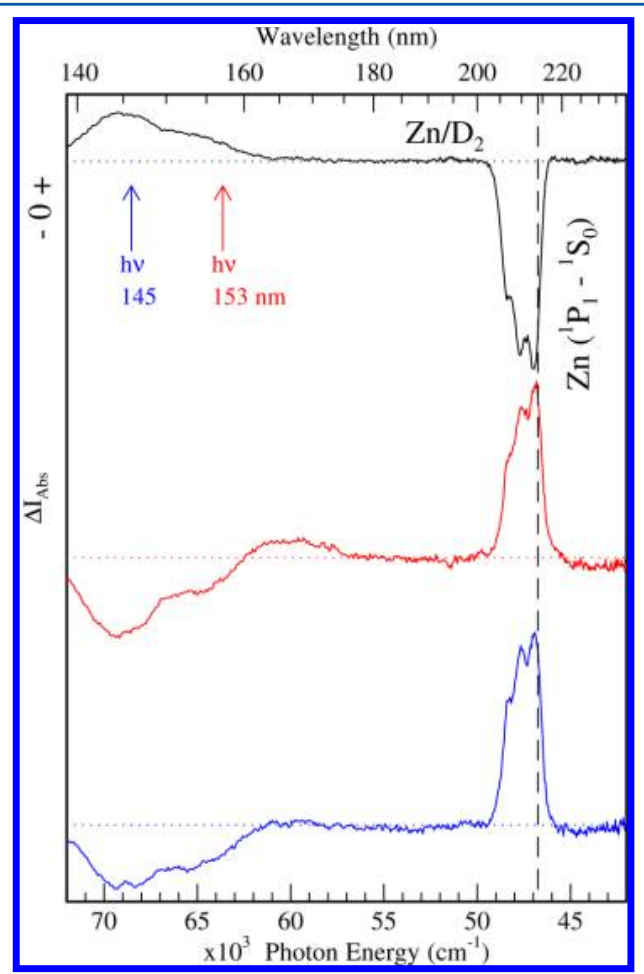

Figure 5. VUV photodissociation of $\mathrm{ZnD}_{2}$ isolated in solid $\mathrm{D}_{2}$ revealing, in the lower two traces, the regeneration of atomic zinc and the depletion of the molecular bands.

resulted in the depletion of both. This depletion was accompanied by the regeneration of the characteristic atomic zinc absorption at $210 \mathrm{~nm}$. After regeneration of atomic zinc, the production of the inserted molecule was shown to be possible once again with atomic photolysis. Thus the insertion/ dissociation cycle could be repeated several times. As a result of this and the characteristic atomic zinc absorption band shape, it is highly likely the other product of the photodissociation is molecular hydrogen and not hydrogen atoms. At the very low temperatures this work was done, some isolation of $\mathrm{H}$ atoms should be possible in the solid hosts. The absence of $\mathrm{H}$ atoms is indicative of a concerted dissociative mechanism whereby both $\mathrm{Zn}-\mathrm{H}$ bonds break at the same time, leading to the formation of an $\mathrm{H}-\mathrm{H}$ bond.

In the $\mathrm{Zn} / \mathrm{CH}_{4}$ system all three VUV molecular bands were found to be photochemically active. Irradiation into any of them resulted (data not shown) in the regeneration of the atomic zinc absorption at $214 \mathrm{~nm}$ and depletion of the new molecular bands. This behavior is similar to that observed by us previously ${ }^{19}$ in the photochemistry of matrix-isolated dimethylzinc (DMZ). However, in contrast to the dissociation of DMZ, where secondary photolysis never regenerated the starting material, methylzinc hydride species could be regenerated with atomic photolysis. This difference stems from the inability of metal atoms to insert into the $\mathrm{C}-\mathrm{C}$ bond of ethane compared to their facile insertion into the $\mathrm{C}-\mathrm{H}$ bonds.

E. TD-DFT Calculations. The electronic absorptions of $\mathrm{ZnH}_{2}$ predicted by TD-DFT calculations are collected in Table 3 for the singlet-singlet transitions. In this table it is evident that the lowest energy transition is from the HOMO (MO 16) 
Table 3. Excitation Energies and Oscillator Strengths for Spin-Allowed Transitions from the Ground X ${ }^{1} \mathrm{~g} \mathrm{State}$ of $\mathrm{ZnH}_{2}{ }^{a}$

\begin{tabular}{|c|c|c|c|c|c|c|}
\hline state no. & orbitals/coeff. & state sym. & $E(\mathrm{eV})$ & $\lambda(\mathrm{nm})$ & $E\left(\mathrm{~cm}^{-1}\right)$ & $f$ \\
\hline 1 & $\begin{aligned} 16 & \rightarrow 17 / 0.31058 \\
16 & \rightarrow 18 / 0.62335\end{aligned}$ & ${ }^{1} \Pi_{\mathrm{g}}$ & 5.7997 & 213.78 & 46777 & 0.0000 \\
\hline 2 & $\begin{array}{l}16 \rightarrow 17 / 0.62335 \\
16 \rightarrow 18 /-0.31058\end{array}$ & ${ }^{1} \Pi_{\mathrm{g}}$ & 5.7997 & 213.78 & 46777 & 0.0000 \\
\hline 3 & $\begin{array}{l}16 \rightarrow 19 / 0.66612 \\
16 \rightarrow 20 /-0.23178\end{array}$ & ${ }^{1} \Sigma_{\mathrm{u}}$ & 7.2816 & 170.27 & 58730 & 0.0910 \\
\hline 4 & $\begin{array}{l}15 \rightarrow 17 / 0.10422 \\
15 \rightarrow 18 / 0.66126\end{array}$ & ${ }^{1} \Pi_{\mathrm{u}}$ & 8.0394 & 154.22 & 64842 & 0.3502 \\
\hline 5 & $\begin{array}{l}15 \rightarrow 17 / 0.66126 \\
15 \rightarrow 18 /-0.10422\end{array}$ & ${ }^{1} \Pi_{\mathrm{u}}$ & 8.0394 & 154.22 & 64842 & 0.3502 \\
\hline 6 & $\begin{array}{l}15 \rightarrow 21 /-0.10725 \\
16 \rightarrow 19 / 0.21522 \\
16 \rightarrow 20 / 0.58930 \\
16 \rightarrow 26 /-0.18648\end{array}$ & ${ }^{1} \Sigma_{\mathrm{u}}$ & 8.1768 & 151.63 & 65950 & 0.7040 \\
\hline 7 & $\begin{array}{l}15 \rightarrow 20 /-0.10301 \\
16 \rightarrow 21 / 0.68731\end{array}$ & ${ }^{1} \Sigma_{\mathrm{g}}$ & 8.3336 & 148.78 & 67213 & 0.0000 \\
\hline 8 & $15 \rightarrow 19 / 0.25477$ & ${ }^{1} \Sigma_{g}$ & 9.0256 & 137.37 & 72796 & 0.0000 \\
\hline 9 & $\begin{array}{l}15 \rightarrow 20 / 0.66992 \\
15 \rightarrow 21 / 0.10189\end{array}$ & ${ }^{1} \Sigma_{g}$ & 9.3425 & 132.71 & 75352 & 0.0000 \\
\hline 10 & $\begin{array}{l}15 \rightarrow 21 /-0.40793 \\
15 \rightarrow 22 / 0.56005\end{array}$ & ${ }^{1} \Sigma_{\mathrm{u}}$ & 9.8924 & 125.33 & 79789 & 0.0217 \\
\hline 11 & $\begin{array}{l}15 \rightarrow 21 / 0.56142 \\
16 \rightarrow 20 / 0.13779 \\
16 \rightarrow 22 / 0.35017\end{array}$ & ${ }^{1} \Sigma_{\mathrm{u}}$ & 10.0716 & 123.10 & 81234 & 0.0003 \\
\hline
\end{tabular}

${ }^{a}$ Only transitions up to approximately $10 \mathrm{eV}$ are provided. Bold font indicates the first allowed transition at $170.3 \mathrm{~nm}$ from the HOMO to the LUMO+1 orbital and the mixture of three electronic transitions that make up the strongest band (see text for details).

to a degenerate LUMO pair of orbitals (MOs 17 and 18) corresponding to the $\mathrm{A}^{1} \Pi_{\mathrm{g}} \leftarrow \mathrm{X}^{1} \Sigma_{\mathrm{g}}^{+}$state transition. This is what is predicted by a qualitative $\mathrm{AH}_{2}$ Walsh-type ${ }^{20}$ diagram for the simplest four-valence electron system. However, from the $f$ values provided in Table 3 , it is clear that while the lowest energy transitions occur at long wavelengths (in the region of the atomic zinc $4 \mathrm{p}^{1} \mathrm{P}_{1} \leftarrow 4 \mathrm{~s}^{1} \mathrm{~S}_{0}$ transition) they have no oscillator strength due to being $\mathrm{g}-\mathrm{g}$ forbidden. Consistent with experimental observations, the first transitions are predicted in the TD-DFT calculation to occur in the VUV. The calculated absorption of $\mathrm{ZnH}_{2}$ is shown by the stick spectrum in the lower panel of Figure S3. Shown also is the spectrum convoluted with a Gaussian function having a line width of $800 \mathrm{~cm}^{-1}$. As indicated in Table 3 , the first allowed transition at $170.3 \mathrm{~nm}$ is from the HOMO to the LUMO+1 orbital. The strongest band, with a convoluted center at approximately $154 \mathrm{~nm}$ is, as specified in Table 3, a mixture of three electronic transitions. It consists of a degenerate ${ }^{1} \Pi$ state at $154 \mathrm{~nm}$ and a ${ }^{1} \Sigma_{\mathrm{u}}$ state at $151.6 \mathrm{~nm}$. The apparent disagreement between the intensities of the stick and convoluted spectra at $154 \mathrm{~nm}$ is an artifact of the presentation which arises due to the degeneracy of the excited ${ }^{1} \Pi$ states at this location.

Shown in the bottom panel of Figure 6 are the absorption spectra recorded for $\mathrm{ZnD}_{2}$ both in a neat $\mathrm{D}_{2}$ solid (red curve) and in a $\mathrm{D}_{2}$-doped Ar matrix (gray curve). By comparing these curves with the convoluted DFT prediction ${ }^{21}$ (black curve, in the upper panel), it is evident that while the predicted bands are approximately in the same spectral region (the discrepancy is $4200 \mathrm{~cm}^{-1}$ ) the shapes are quite different. In particular a strong band consisting of two unresolved components of roughly equal intensity and a much weaker red band are predicted, while a broad structure consisting of a dominant band and a strong red shoulder are observed (red/gray traces in the lower

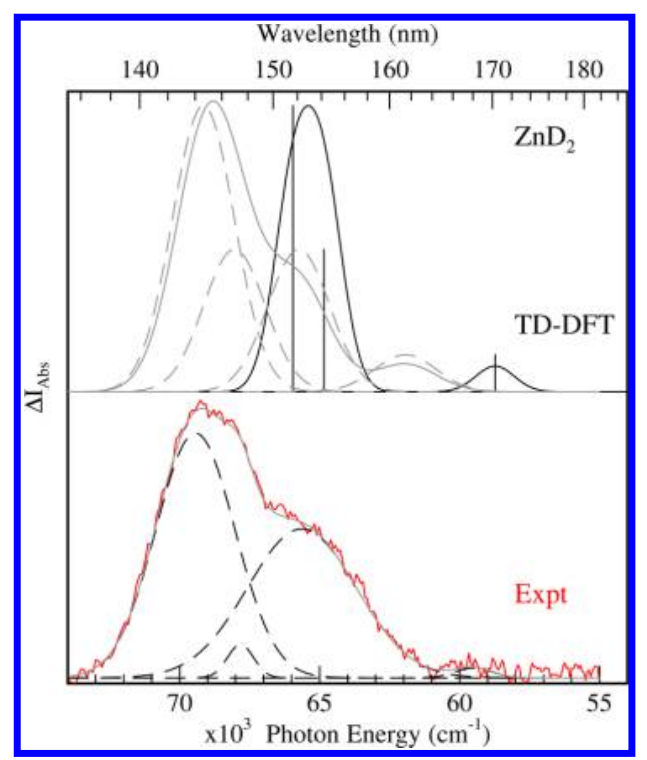

Figure 6. Comparison of the TD-DFT predicted (convoluted) excitation energies with the absorption spectra of $\mathrm{ZnD}_{2}$. The dashed curves in the lower panel are those obtained by fitting four Gaussian curves to the recorded data. Their sum is shown by the gray curve overlaid on the experimental data, shown in red. The solid black traces in the upper panel are the stick and convoluted predicted spectra. To obtain a match with the recorded data, the gray traces were generated by blue shifting the original TD-DFT bands by $4200 \mathrm{~cm}^{-1}$ (shown by the solid black trace) and splitting the degenerate $\Pi$ state by 2200 $\mathrm{cm}^{-1}$. The curve generated by summing the dashed curves is shown by the solid gray trace, and it can be compared with the experimental data in the lower panel. 
panel). From the TD-DFT calculation it is known (see Table 3 ) that the transition at $154 \mathrm{~nm}$ is to a ${ }^{1} \Pi$ state, and it has been observed that the degeneracy of such states is often removed by the symmetry of the site accommodating the guest molecule in the solid matrix.

In an attempt to account for the observed bands, the TDDFT transitions are all blue-shifted by $4200 \mathrm{~cm}^{-1}$, and the ${ }^{1} \Pi$ state has been split by $2200 \mathrm{~cm}^{-1}$, the result of which is shown by the four dashed curves in the upper panel of Figure 6 . In so doing, a line width of $1050 \mathrm{~cm}^{-1}$ was used for each of the bands, and for all of them, a constant shift was applied. However, the predicted transitions intensities were not adjusted from the $f$-values obtained directly from the TD-DFT calculation and listed in Table 3. Addition of these four components (dashed curves) generates the solid black trace shown overlaid on the recorded $\mathrm{ZnD}_{2}$ spectra in the lower panel of Figure 6. The agreement is quite good; however, one aspect made evident in the comparison shown in Figure 6 is the existence of a lower energy band of $\mathrm{ZnD}_{2}$ at approximately $60000 \mathrm{~cm}^{-1}$. This feature is not immediately obvious in the experimental spectra, in part due to the weakness of this band but also the poor signal-to-noise ratio.

In Figure 7 the absorption spectra of $\mathrm{CH}_{3} \mathrm{ZnH}$ recorded in neat methane (red trace) and in $\mathrm{CH}_{4}$-doped $\mathrm{Ar}$ (gray trace)

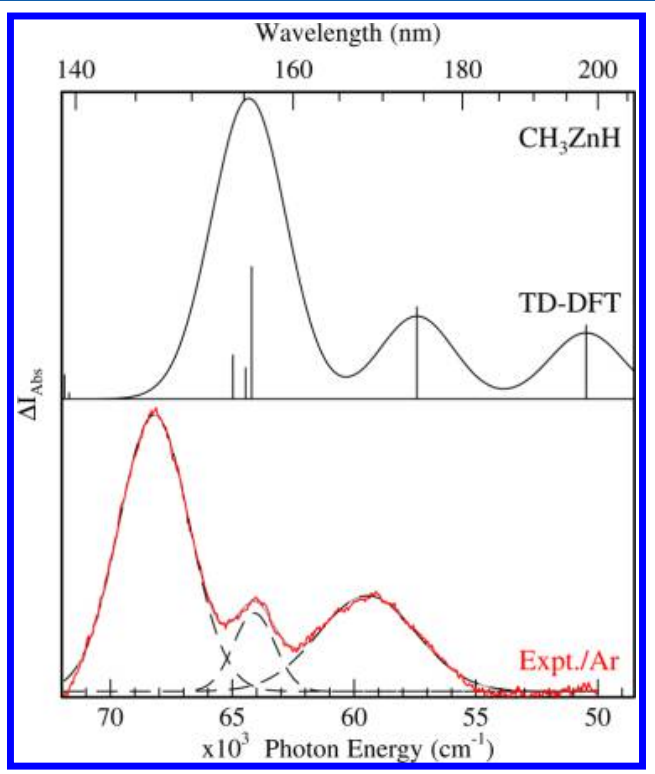

Figure 7. Similar comparison to Figure 6 but for $\mathrm{CH}_{3} \mathrm{ZnH}$ results. Three bands are sufficient to provide an acceptable fit of the recorded absorption bands. No splitting was used on the degenerate $\mathrm{E}$ state as it already has cylindrical symmetry in this $C_{3 v}$ molecule. A constant shift does not allow the three convoluted bands to match the three recorded bands. In this system, a blue shift of $5200 \mathrm{~cm}^{-1}$ lines up the central band in the pure $\mathrm{CH}_{4}$ system. However, it is evident that this constant shift underestimates the location of the red band and overestimates the blue band.

matrices are compared with a TD-DFT calculated electronic spectrum. When a comparison of both is made, it is evident that there is reasonable agreement between the broadened TD-DFT spectrum (black trace in upper panel) and the experimental spectrum. Thus three well-resolved peaks are predicted consisting of a strong blue band and two weaker red bands of equal intensity. As is evident in the lower panel of Figure 7, the recorded bands show this behavior as best illustrated in the
doped-Ar system. However, as was observed in the $\mathrm{ZnH}_{2}$ system the predicted bands are all at lower energy than the recorded bands. In the comparison shown, the intensities of the TD-DFT calculated bands have not been altered. Other details of the fit are provided in the caption of Figure 7.

\section{DISCUSSION}

A. Metal Atom Spectroscopy. The absorption bandwidth (total fwhm $2100 \mathrm{~cm}^{-1}$ ) of the atomic $4 \mathrm{p}^{1} \mathrm{P}_{1} \leftarrow 4 \mathrm{~s}^{1} \mathrm{~S}_{0}$ transition in solid $\mathrm{D}_{2}$ is, as depicted in Figure 1, considerably greater than that of atomic zinc in the other light solids examined, namely, methane, and neon. Indeed it is much greater than what has been observed ${ }^{12}$ for the rare gases, $\mathrm{Ar}, \mathrm{Kr}$, and Xe. However, it is in line with values of 1500 and 1200 $\mathrm{cm}^{-1}$ measured for atomic magnesium ${ }^{22}$ and lithium, ${ }^{23}$ respectively, in solid hydrogen. On the other hand, the 3-fold splitting recorded in the $\mathrm{Zn} / \mathrm{D}_{2}$ system is much better resolved than in the previous work done on $\mathrm{Mg}$ in $\mathrm{H}_{2}, \mathrm{HD}$, or $\mathrm{D}_{2}$. From the spectra recorded for $\mathrm{Li}^{23}$ isolated in the solid hydrogens, it is not clear that 3 -fold splitting exists in this system. The reason for the difference between zinc and the other metal atom systems is likely related to the smaller van der Waals radius of atomic zinc in the $\mathrm{Zn} \cdot \mathrm{RG}$ diatomics.

Since the zinc atom-hydrogen molecule $\left(\mathrm{Zn} \cdot \mathrm{D}_{2}\right)$ van der Waals distance is not yet known, one cannot definitively confirm this proposal. However, spectroscopic work on 1:1 metal atom/rare gas atom van der Waals complexes has revealed that, of the metals in question $(\mathrm{Li}, \mathrm{Mg}$, and $\mathrm{Zn})$, the zinc-containing species have the shortest bond lengths. Given that the nearest neighbor $(\mathrm{nn})$ distance ${ }^{24}$ in solid $\mathrm{H}_{2}$ is $3.79 \AA$, considerably greater than the $\mathrm{nn}$ distance in solid neon (3.09 $\AA$ ) but very similar to that of solid $\operatorname{Ar}(3.76 \AA)$, it is reasonable to propose that the same site occupancy will occur in solid $\mathrm{H}_{2}$ as solid argon. The results of a combined experimental/pairpotentials $^{25}$ simulation $^{26}$ suggest occupancy of atomic zinc in single vacancy (substitutional) site of argon. Thus, it is plausible that atomic zinc resides in a substitutional site in $\mathrm{D}_{2}$. This proposal is supported by the similarity of the 3-fold splitting revealed in the line shape fits presented in Figure S1 for $\mathrm{Zn} / \mathrm{Ar}$ and $\mathrm{Zn} / \mathrm{D}_{2}$ matrices. The much greater bandwidth of the latter system $\left(742 \mathrm{~cm}^{-1}\right)$ compared with $\operatorname{Ar}\left(412 \mathrm{~cm}^{-1}\right.$, see Table 2) arises from the high phonon frequency of $\mathrm{D}_{2}$ which is a lowmass, quantum solid.

As a result of the foregoing considerations of the size of atomic zinc, it is likely the site accommodating this guest is more symmetric than the distorted lattices accompanying isolation of the larger atoms $\mathrm{Li}$ and $\mathrm{Mg}$ if substitutional occupancies are also present for these guests. Moreover, the proposal of this site occupancy is consistent with the much more efficient isolation of atomic zinc in solid $\mathrm{D}_{2}$ than in solid neon as revealed in the absorption spectra shown in Figure 1. Multivacancy occupancy has been proposed ${ }^{11}$ for the site of isolation of atomic zinc in solid neon.

B. Zinc Dideuteride Spectroscopy. The most likely candidate for the VUV absorption bands (shown in Figure 3) produced after atomic zinc photolysis in solid deuterium is zinc dideuteride, $\mathrm{ZnD}_{2}$. This molecule has been definitively identified in FTIR work ${ }^{5}$ of matrix-isolated atomic zinc in rare gases containing small amounts of hydrogen (and its isotopologues). The results obtained by Wang and Andrews ${ }^{4}$ for the reaction of atomic zinc in the solid para-hydrogen (and solid ortho-deuterium) confirm these assignments. The proposed mechanism for the formation of the $\mathrm{ZnD}_{2}$ molecule 
Table 4. Excitation Energies and Oscillator Strengths for Spin Allowed Transitions from the Ground $\mathrm{X}^{1} \mathrm{~A}_{1} \mathrm{State}$ of $\mathrm{CH}_{3} \mathrm{ZnH}^{a}$

\begin{tabular}{|c|c|c|c|c|c|c|}
\hline state no. & orbitals/coeff. & state sym. & $E(\mathrm{eV})$ & $\lambda(\mathrm{nm})$ & $E\left(\mathrm{~cm}^{-1}\right)$ & $f$ \\
\hline 1 & $20 \rightarrow 21 / 0.69950$ & ${ }^{1} \mathrm{E}$ & 5.6516 & 219.38 & 45583 & 0.0006 \\
\hline 2 & $20 \rightarrow 22 / 0.69950$ & ${ }^{1} \mathrm{E}$ & 5.6516 & 219.38 & 45583 & 0.0006 \\
\hline 3 & $20 \rightarrow 23 / 0.68162$ & ${ }^{1} \mathrm{~A}_{1}$ & 6.2587 & 198.10 & 50479 & 0.1425 \\
\hline 4 & $20 \rightarrow 24 / 0.70006$ & ${ }^{1} \mathrm{~A}_{1}$ & 7.1196 & 174.15 & 57421 & 0.1784 \\
\hline \multirow[t]{2}{*}{5} & $19 \rightarrow 22 /-0.13028$ & ${ }^{1} \mathrm{~A}$ & 7.6537 & 161.99 & 61732 & 0.0001 \\
\hline & $20 \rightarrow 26 / 0.69002$ & & & & & \\
\hline \multirow[t]{2}{*}{6} & $19 \rightarrow 21 /-0.13030$ & ${ }^{1} \mathrm{E}$ & 7.6537 & 161.99 & 61732 & 0.0001 \\
\hline & $20 \rightarrow 25 / 0.69001$ & & & & & \\
\hline \multirow[t]{2}{*}{7} & $19 \rightarrow 22 / 0.65977$ & ${ }^{1} \mathrm{E}$ & 7.9604 & 155.75 & 64205 & 0.2562 \\
\hline & $20 \rightarrow 26 / 0.13528$ & & & & & \\
\hline \multirow[t]{2}{*}{8} & $19 \rightarrow 21 / 0.65977$ & ${ }^{1} \mathrm{E}$ & 7.9604 & 155.75 & 64205 & 0.2562 \\
\hline & $20 \rightarrow 25 / 0.13530$ & & & & & \\
\hline \multirow[t]{2}{*}{9} & $19 \rightarrow 23 / 0.48778$ & ${ }^{1} \mathrm{~A}_{1}$ & 7.9907 & 155.16 & 64449 & 0.0603 \\
\hline & $20 \rightarrow 27 / 0.47850$ & & & & & \\
\hline \multirow[t]{3}{*}{10} & $19 \rightarrow 23 / 0.47674$ & ${ }^{1} \mathrm{~A}_{1}$ & 8.0550 & 153.92 & 64968 & 0.0846 \\
\hline & $20 \rightarrow 27 /-0.43952$ & & & & & \\
\hline & $20 \rightarrow 28 / 0.20483$ & & & & & \\
\hline \multirow[t]{7}{*}{11} & $17 \rightarrow 22 / 0.30565$ & ${ }^{1} \mathrm{~A}_{1}$ & 8.8590 & 139.95 & 71454 & 0.0002 \\
\hline & $18 \rightarrow 21 / 0.30487$ & & & & & \\
\hline & $19 \rightarrow 23 /-0.10968$ & & & & & \\
\hline & $19 \rightarrow 24 / 0.31292$ & & & & & \\
\hline & $19 \rightarrow 27 /-0.12589$ & & & & & \\
\hline & $20 \rightarrow 28 / 0.37893$ & & & & & \\
\hline & $20 \rightarrow 29 / 0.17783$ & & & & & \\
\hline \multirow[t]{3}{*}{12} & $17 \rightarrow 21 / 0.10735$ & ${ }^{1} \mathrm{E}$ & 8.8887 & 139.48 & 71695 & 0.0117 \\
\hline & $18 \rightarrow 22 / 0.108 .19$ & & & & & \\
\hline & $20 \rightarrow 31 / 0.68659$ & & & & & \\
\hline \multirow[t]{3}{*}{13} & $17 \rightarrow 22 / 0.10735$ & ${ }^{1} \mathrm{E}$ & 8.8887 & 139.478 & 71695 & 0.0117 \\
\hline & $18 \rightarrow 21 /-0.10840$ & & & & & \\
\hline & $20 \rightarrow 30 / 0.68661$ & & & & & \\
\hline \multirow[t]{2}{*}{14} & $17 \rightarrow 21 / 0.49798$ & ${ }^{1} \mathrm{~A}_{2}$ & 8.9005 & 139.30 & 71787 & 0.0000 \\
\hline & $18 \rightarrow 22 /-0.49783$ & & & & & \\
\hline \multirow[t]{2}{*}{15} & $20 \rightarrow 28 /-0.32111$ & ${ }^{1} \mathrm{~A}_{1}$ & 8.9127 & 139.11 & 71885 & 0.0467 \\
\hline & $20 \rightarrow 29 / 0.61493$ & & & & & \\
\hline
\end{tabular}

${ }^{a}$ Only transitions up to approximately $9 \mathrm{eV}$ are provided.

is the insertion of the excited ${ }^{1} \mathrm{P}_{1}$ state $\mathrm{Zn}$ atom into the $\mathrm{D}-\mathrm{D}$ bond and the stabilization of the resulting intermediate in the low temperature solid. Gas-phase pump-probe studies ${ }^{9,27}$ of this reaction propose a similar species in the process of forming $\mathrm{Zn}-\mathrm{H}+\mathrm{H}$. Moreover, the linear triatomics $\mathrm{ZnH}_{2}$ and $\mathrm{ZnD}_{2}$ have indeed been generated in the gas phase in a hightemperature furnace-discharge as observed ${ }^{1}$ in emission in the mid-IR region.

The absorption bands of zinc dideuteride, $\mathrm{ZnD}_{2}$ (Figure 3) and methylzinc hydride, $\mathrm{CH}_{3} \mathrm{ZnH}$ (Figure 4), are featureless in the VUV spectral region. This characteristic arises because the excited states involved have all been shown to be dissociative. As indicated in Figures 6 and 7, the TD-DFT predicted spectra exhibit the right number of bands which are approximately in the correct spectral region for both species. However, they do require blue shifting of about $0.5 \mathrm{eV}$ to achieve numerical agreement with the recorded data. The reason for this shift appears to be different for the two species. Thus, in $\mathrm{CH}_{3} \mathrm{ZnH}$, a part of this effect arises from a matrix shift in the experimental spectra. This is revealed in the comparison of the pure methane data and the doped methane-Ar results, presented in the upper panel of Figure S2, which indicates the latter is blue-shifted against neat methane. The matrix shift arises due to the different interaction strengths between the guest species and the two host materials. As the site sizes and host polarizabilities of solid $\mathrm{CH}_{4}$ and $\mathrm{Kr}$ are very similar, the blue shift in Ar would indicate a repulsive interaction of the excited state guest molecule in its solid environment. This in turn would suggest $\mathrm{CH}_{3} \mathrm{ZnH}$ resides in a cramped site in argon compared with methane.

In $\mathrm{ZnD}_{2}$ by contrast, the matrix shift appears to be nonexistent (see the lower panel of Figure S2). Even so, the theoretically predicted bands are red-shifted by about 4000 $\mathrm{cm}^{-1}$ (Figure 6). A possible reason for the difference is that the large Franck-Condon (FC) factors which accompany these dissociative electronic transitions are not included in the absorption band profiles generated in the present TD-DFT calculations. With the ultracold conditions used to record the absorption spectra, large FC factors will extend the TD-DFT calculated spectra to the blue-shift of the calculated vertical transition energies. The simple Gaussian convolutions done in the present simulations are evenly distributed around the electronic band origin and do not address this FC effect.

Another possible reason for the $0.5 \mathrm{eV}$ discrepancy could be due to inherent errors ${ }^{28,29}$ in the TD-DFT method itself. A rough indicator of the inaccuracy of a TD-DFT calculation is provided by the negative of the highest occupied Kohn-Sham (KS) orbital energy. Thus when the calculated excitation 


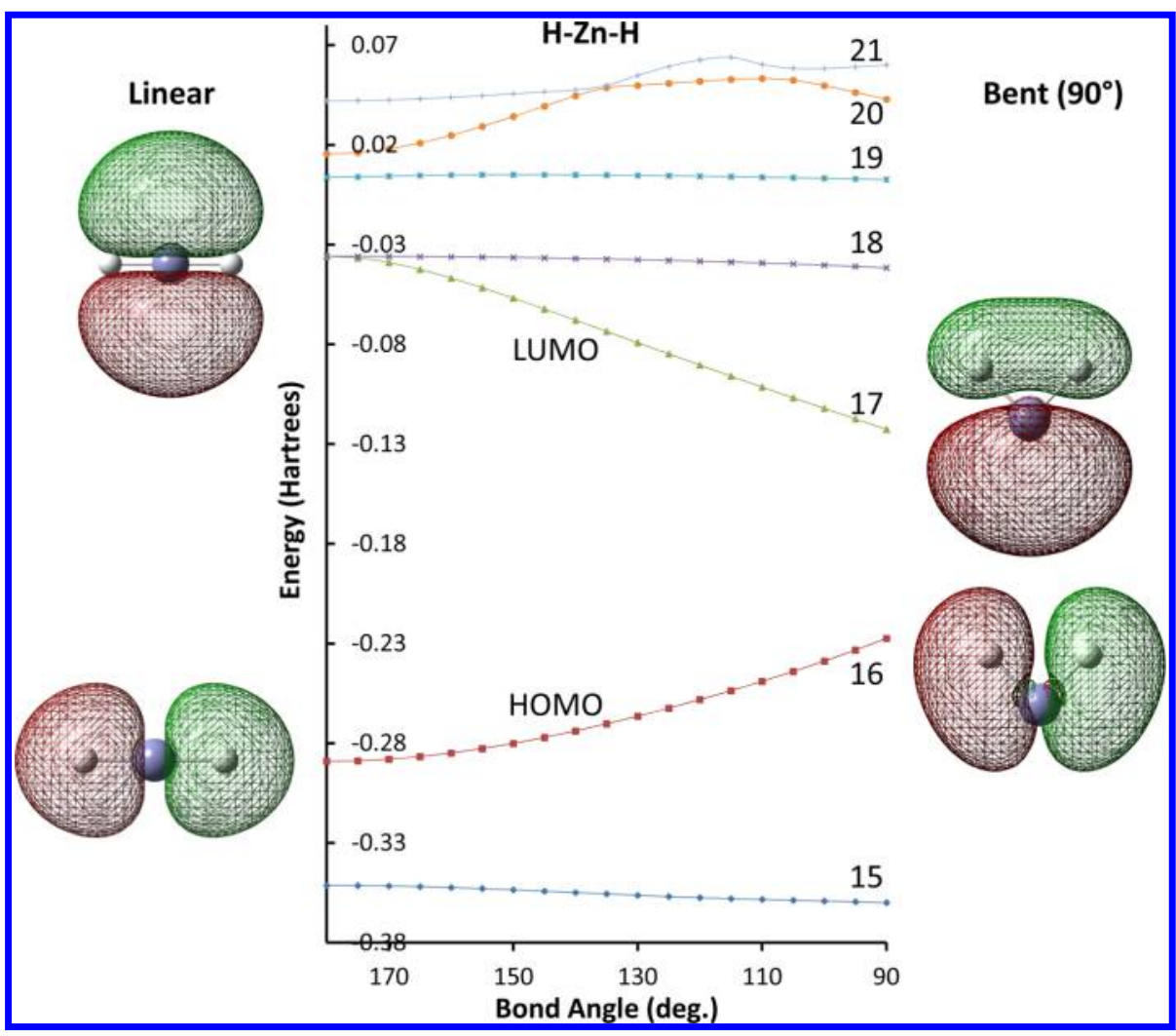

Figure 8. A Walsh diagram calculated with the DFT method for $\mathrm{HZnH}$. In performing this calculation, the $\mathrm{Zn}-\mathrm{H}$ bond lengths were optimized for each specific angle. The four MO's shown present the shapes of the HOMO and LUMO for the linear and bent $\left(90^{\circ}\right)$ geometries.

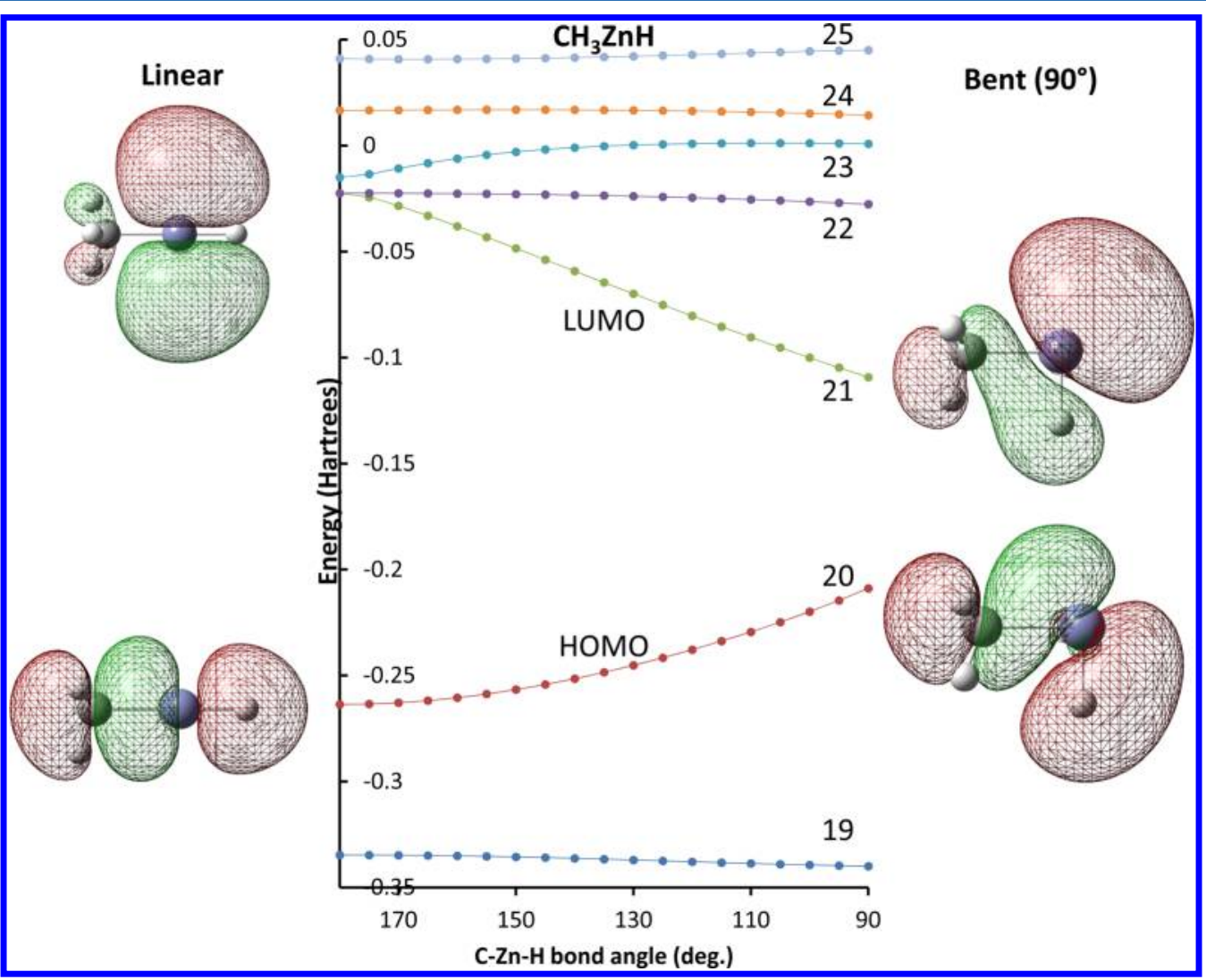

Figure 9. A Walsh diagram calculated for $\mathrm{CH}_{3} \mathrm{ZnH}$ with the DFT method as a function of the $\mathrm{C}-\mathrm{Zn}-\mathrm{H}$ angle. In doing this calculation, all of the bond lengths were optimized for each specific angle. 
energies approach this threshold, the predicted values are likely to be underestimated relative to experimental results. Following this rough accuracy guide, the negative of the HOMO energy of $\mathrm{ZnH}_{2}\left(\mathrm{CH}_{3} \mathrm{ZnH}\right)$ is 63445.7 (57855.7) $\mathrm{cm}^{-1}$, and the first allowed transition is, as listed in Tables 3 and 4, less than this, having a value of $58730(50479) \mathrm{cm}^{-1}$. From these comparisons we expect that, while not an ideal situation, the B3LYP functional (with the large basis set used) should allow the TD-DFT method to provide a reasonable prediction of the excitation energies. Indeed, the underestimate of the predicted transition energies is less than $6 \%(0.5 \mathrm{eV})$ on the allowed transitions in the $8 \mathrm{eV}$ region. It should be mentioned that the TD-DFT method also underestimates the atomic zinc $4 \mathrm{p}^{1} \mathrm{P}_{1}$ $\leftarrow 4 \mathrm{~s}^{1} \mathrm{~S}_{0}$ transition but by a somewhat smaller amount. Thus the gas phase value is known ${ }^{17}$ to be $46745.413 \mathrm{~cm}^{-1}$, while the predicted value is $45531 \mathrm{~cm}^{-1}$ - corresponding to an underestimate of $2.6 \%$.

C. Photochemistry. The dissociative activity exhibited by the VUV bands of $\mathrm{ZnD}_{2}$ and $\mathrm{CH}_{3} \mathrm{ZnH}$ upon photolysis is consistent with the featureless nature of these absorption bands. This behavior can be related to the bonding described for a four-electron $\mathrm{AH}_{2}$ system by a Walsh diagram. Thus the ground state is, as observed experimentally, predicted to be linear in this simple bonding model. The first excited states on the other hand are expected to be bent due to strong stabilization of the LUMO orbital upon bending.

To investigate the observed photodissociation of $\mathrm{ZnH}_{2}$ and $\mathrm{CH}_{3} \mathrm{ZnH}$, we explored the evolution of the orbital energies of both molecules from the linear to bent geometries. In analyzing this we present in Figures 8 and 9 graphs of the $\mathrm{ZnH}_{2}$ and $\mathrm{CH}_{3} \mathrm{ZnH} \mathrm{MO}$ energies between $180^{\circ}$ and $90^{\circ}$, calculated in $5^{\circ}$ increments. Also included are the MO shapes as determined in Gaussian 03. From Figure 8, it can be seen that when $\mathrm{ZnH}_{2}$ is in the ground state and the HOMO is occupied, the linear form is more stable than the bent. When it absorbs at $154 \mathrm{~nm}$, one of the valence electrons in MO15 (HOMO-1) is promoted to the LUMO (MO's 17/18) as indicated in Table 3. In the excited state it can be seen that the bent form of $\mathrm{ZnH}_{2}$ is actually more stable than the linear. The angle dependence of the energy of $\mathrm{MO} 17$ is the reason for the change in geometry. MO17 of $\mathrm{ZnH}_{2}$ in the linear geometry consists of a nonbonding p-orbital centered on the $\mathrm{Zn}$ atom, as depicted on the top left of Figure 8 . The bent form contains the same nonbonding p-orbital, but in this geometry (see top right of Figure 8) the s-orbitals overlap between the two hydrogen atoms. Arising from this change is the formation of an $\mathrm{H}-\mathrm{H}$ bond. Moreover, as there is also no electron density over the $\mathrm{Zn}$ and $\mathrm{H}$ atoms, breakage of the $\mathrm{Zn}-\mathrm{H}$ bond results. It is this evolution of MO17 which leads to the photodissociation of $\mathrm{ZnH}_{2}$ and the formation of atomic zinc and molecular hydrogen.

A similar but more complex behavior was found in methylzinc hydride as shown in Figure 9. However, just as in the $\mathrm{ZnH}_{2}$ system, at $90^{\circ} \mathrm{MO} 21$ of $\mathrm{CH}_{3} \mathrm{ZnH}$ shows the reformation of a $\mathrm{C}-\mathrm{H}$ bond from the hydrogen that was bonded to the zinc atom. A node is also evident (see top right of Figure 9) between the zinc atom and the $\mathrm{CH}_{3} \cdots \mathrm{H}$ moiety. The angle dependence found in the TD-DFT calculations of the LUMO energies is identified as responsible for the clean, concerted dissociation of the VUV bands in the case of both molecules. This is the classic behavior predicted by a simple four-valence electron $\mathrm{AH}_{2}$ Walsh-type diagram.

In contrast to the aforementioned behavior, correctly anticipated by a Walsh diagram, it is noteworthy that the shape of the energy curve of the stabilized LUMO (MO17) of $\mathrm{ZnH}_{2}\left(\mathrm{CH}_{3} \mathrm{ZnH}, \mathrm{MO} 21\right)$ becomes almost linear after only a small (approximately $15^{\circ}$ ) angle deviation from $180^{\circ}$ while the shape of the destabilized HOMO energy, MO16 (MO20), is curved over the entire angle range. As Figures 8 and 9 respectively reveal, $\mathrm{ZnH}_{2}$ and $\mathrm{CH}_{3} \mathrm{ZnH}$ both show this same behavior. The curved behavior of the HOMO energy can be traced back to the angle dependence of the overlap between the $\mathrm{Zn}$ atom p-orbital and the $\mathrm{H}$-atom s-orbital. As such, it will simply exhibit a cosine dependence as is well-illustrated in Figure S4. By contrast the cosine dependence of the LUMO is limited to small angle deviation from the linear geometry. Thereafter, the energy of this orbital is stabilized by the formation of the new $\mathrm{H}-\mathrm{H}$ bond. This contributing effect is usually not considered in textbook descriptions of $\mathrm{AH}_{2}$ Walsh diagrams.

\section{CONCLUSIONS}

The absorption spectra of $\mathrm{ZnD}_{2}$ and $\mathrm{CH}_{3} \mathrm{ZnH}$ have been recorded for the first time in the vacuum-UV range. These "inserted" species were produced from the efficient reaction of excited ${ }^{1} \mathrm{P}_{1}$ state atomic zinc with the molecular precursors $\mathrm{D}_{2}$ and $\mathrm{CH}_{4}$. Emission of the ${ }^{1} \mathrm{P}_{1}$ state was completely quenched in both solid $\mathrm{D}_{2}$ and $\mathrm{CH}_{4}$; however, ${ }^{3} \mathrm{P}$ state luminescence of atomic zinc was observed in the $\mathrm{Zn} / \mathrm{CH}_{4}$ system. The latter observation points to the involvement of the spin triplet state in the relaxation of the lower symmetry $\mathrm{CH}_{3} \mathrm{ZnH}$ system as it evolves into the $C_{3 v}$ ground state geometry. This state appears to play no role in the stabilization of $\mathrm{ZnD}_{2}$. TD-DFT calculations provide reliable descriptions of the excited states responsible for the VUV absorptions of $\mathrm{ZnH}_{2}$ and $\mathrm{CH}_{3} \mathrm{ZnH}$; however, all of the predicted transition energies are underestimates of the observed bands. Large Franck-Condon factors may partly explain the blue-location of the observed bands relative to the vertical excitations generated in the TD-DFT calculations. The observed photodissociation of these molecules has been modeled successfully with Walsh-type diagrams generated from the DFT calculations.

\section{ASSOCIATED CONTENT}

\section{S Supporting Information}

Lineshape analyses of absorption profiles for $\mathrm{Zn} / \mathrm{D}_{2}, \mathrm{Zn} / \mathrm{CH}_{4}$, and $\mathrm{Zn} / \mathrm{Ar}$ (Figure S1), a comparison of the VUV absorption bands produced in $\mathrm{Zn} / \mathrm{D}_{2}$ and $\mathrm{Zn} / \mathrm{CH}_{4}$ systems (Figure S2), a comparison of the TD-DFT predictions for the electronic transitions of $\mathrm{CH}_{3} \mathrm{ZnH}$ and $\mathrm{H}-\mathrm{Zn}-\mathrm{H}$ (Figure S3), DFT calculated overlap dependence of the $\mathrm{Zn} 4 \mathrm{p}$ orbital and $\mathrm{H}$ atom 1s orbital (Figure S4), comparison of band origins (Table S1), and band positions extracted by free-fitting Gaussan curves to the recorded absorption data (Table S2). This material is available free of charge via the Internet at http://pubs.acs.org.

\section{AUTHOR INFORMATION}

\section{Corresponding Author}

*E-mail: john.mccaffrey@nuim.ie.

\section{Notes}

The authors declare no competing financial interest.

\section{ACKNOWLEDGMENTS}

We would like to acknowledge Dr. Peter Gürtler and Dr. Sven Petersen for technical assistance with the experimental work done at the HASYLAB synchrotron. This research was funded 
in part by the European Union, TMR, "Access to Large Scale Facilities” Programme. C.H. also gratefully acknowledges receipt of a Hume Ph.D. studentship, at NUI-Maynooth.

\section{REFERENCES}

(1) Shayesteh, A.; Gordon, I. E.; Appadoo, D. R. T.; Bernath, P. F. Infrared emission spectra and equilibrium bond lengths of gaseous $\mathrm{ZnH}_{2}$ and $\mathrm{ZnD}_{2}$. Phys. Chem. Chem. Phys. 2005, 7 (17), 3132-3142.

(2) Sebald, P.; Vennekate, H.; Oswald, R.; Botschwina, P.; Stoll, H. A theoretical study of $\mathrm{ZnH}_{2}$ : a case of very strong Darling-Dennison resonance. Mol. Phys. 2010, 108 (3-4), 487-499.

(3) Flory, M. A.; Apponi, A. J.; Zack, L. N.; Ziurys, L. M. Activation of Methane by Zinc: Gas-Phase Synthesis, Structure, and Bonding of $\mathrm{HZnCH}_{3}$. J. Am. Chem. Soc. 2010, 132 (48), 17186-17192.

(4) Wang, X.; Andrews, L. Infrared Spectra of $\mathrm{Zn}$ and Cd Hydride Molecules and Solids. J. Phys. Chem. A 2004, 108 (50), 11006-11013.

(5) Greene, T. M.; Andrews, L.; Downs, A. J. The Reaction of Zinc, Cadmium, and Mercury Atoms with Methane: Infrared Spectra of the Matrix-Isolated Methylmetal Hydrides. J. Am. Chem. Soc. 1995, 117 (31), 8180-7.

(6) Bracken, V. A.; Legay-Sommaire, N.; McCaffrey, J. G. Spectroscopy and Photodissociation of Dimethylzinc in Solid Argon. 2. FTIR Detection/ArF Laser Photolysis. J. Phys. Chem. A 1997, 101 (51), 9863-9869.

(7) Breckenridge, W. H. Activation of $\mathrm{H}-\mathrm{H}, \mathrm{Si}-\mathrm{H}$, and C-H Bonds by nsnp Excited States of Metal Atoms. J. Phys. Chem. 1996, 100 (36), 14840-14855.

(8) Breckenridge, W. H.; Wang, J. H. Dynamics of the reactions of $\operatorname{zinc}\left(4 s 4 \mathrm{p}^{3} \mathrm{P}_{1}\right)$ with hydrogen, hydrogen deuteride, and deuterium: rotational and vibrational quantum-state distributions of zinc hydride (zinc deuteride) $(\mathrm{ZnH}(\mathrm{ZnD}))$ products. J. Chem. Phys. 1987, 87 (5), 2630-7.

(9) Umemoto, H.; Tsunashima, M.; Tsunashima, S.; Ikeda, H. Nascent vibrational state distributions of $\mathrm{ZnH}\left(\mathrm{X}^{2} \Sigma^{+}\right)$and $\mathrm{ZnD}\left(\mathrm{X}^{2} \Sigma^{+}\right)$ produced in the reactions of $\mathrm{Zn}\left(4^{1} \mathrm{P}_{1}\right)$ with $\mathrm{H}_{2}$ and $\mathrm{D}_{2}$. Laser Chem. 1995, 15 (2-4), 123-9.

(10) Martinez-Magadan, J. M.; Ramirez-Solis, A.; Novaro, O. MCSCF + MR-CI study of the interaction of atomic zinc, and zinc(1+) and $\operatorname{zinc}(2+)$ ions with the hydrogen molecule. Chem. Phys. Lett. 1991, 186 (1), 107-12.

(11) Healy, B.; Kerins, P.; McCaffrey, J. G. Metal atom (Zn, Cd and $\mathrm{Mg}$ ) luminescence in solid neon. Low Temp. Phys. 2012, 38 (8), 679687.

(12) Bracken, V. A.; Gurtler, P.; McCaffrey, J. G. Luminescence spectroscopy of atomic zinc in rare-gas solids. I. J. Chem. Phys. 1997, 107 (14), 5290-5299.

(13) Collier, M. A.; McCaffrey, J. G. Luminescence spectroscopy of matrix-isolated z6P state atomic manganese. J. Chem. Phys. 2005, 122 (18), 184507/1-184507/15.

(14) Frisch, M. J., et al. Gaussian-03, Revision E.01; Gaussian, Inc.: Wallingford, CT, 2004.

(15) Murray, C.; Dozova, N.; McCaffrey, J. G.; Shafizadeh, N.; Chin, W.; Broquier, M.; Crepin, C. Visible luminescence spectroscopy of free-base and zinc phthalocyanines isolated in cryogenic matrixes. Phys. Chem. Chem. Phys. 2011, 13 (39), 17543-17554.

(16) Alikhani, M. E. Theoretical study of the insertion reaction of zinc, cadmium, and mercury atoms with methane and silane. Chem. Phys. Lett. 1999, 313 (3), 608-616.

(17) NIST Atomic Spectra Database, Version 4; National Institute of Standards and Technology: Gaithersburg, MD, 2013; http://www.nist. gov/pml/data/asd.cfm (available: May 2013).

(18) Because of the high repetition rate of the SR excitation pulses, direct measurement of the $\mathrm{Zn} / \mathrm{CH}_{4}$ near-UV emission decaytimes was not possible. Even for "single-bunch" mode operation, when the repetition rate of the storage ring is reduced to $1.042 \mathrm{MHz}$, this was still too high indicating a very long-lived emission. Accordingly it is inferred that the decay time of the near-UV emissions must be longer than $10 \mu \mathrm{s}$.
(19) Bracken, V. A.; Guertler, P.; McCaffrey, J. G. Spectroscopy and Photodissociation of Dimethylzinc in Solid Argon. 1. Vacuum UV Luminescence Detection/Synchrotron Radiation Photolysis. J. Phys. Chem. A 1997, 101 (51), 9854-9862.

(20) Gimarc, B. M. Molecular Structure and Bonding; Academic Press: New York, 1979 Chapter 3.

(21) In Figure 9 theoretical predictions for $\mathrm{ZnH}_{2}$ are used in a comparison with the experimental data recorded for $\mathrm{ZnD}_{2}$. This is possible because the electronic spectroscopy is not dependent on the masses of the isotopes.

(22) Presser, N. Spectroscopy of magnesium in hydrogenic matrixes. Chem. Phys. Lett. 1992, 199 (1-2), 10-16.

(23) Fajardo, M. E. Matrix-isolation spectroscopy of metal atoms generated by laser ablation. II. The lithium/neon, lithium/deuterium, and lithium/hydrogen systems. J. Chem. Phys. 1993, 98 (1), 110-18.

(24) Silvera, I. F. The solid molecular hydrogens in the condensed phase: fundamentals and static properties. Rev. Mod. Phys. 1980, 52 (2, Pt. 1), 393-452.

(25) Kerins, P. N.; McCaffrey, J. G. A pair potentials study of matrixisolated atomic zinc. I. Excited ${ }^{1} \mathrm{P}_{1}$ state dynamics in solid Ar. J. Chem. Phys. 1998, 109 (8), 3131-3136.

(26) Healy, B.; McCaffrey, J. G. Simulation of atomic cadmium spectroscopy in rare gas solids using pair potentials. J. Phys. Chem. A 2000, 104 (16), 3553-3562.

(27) Umemoto, H.; Tsunashima, S.; Ikeda, H.; Takano, K.; Kuwahara, K.; Sato, K.; Yokoyama, K.; Misaizu, F.; Fuke, K. Nascent internal state distributions of $\mathrm{ZnH}\left(\mathrm{X}^{2} \Sigma^{+}\right)$produced in the reactions of $\mathrm{Zn}\left({ }^{1} \mathrm{P}_{1}\right)$ with some alkane hydrocarbons. J. Chem. Phys. 1994, 101 (6), 4803-8.

(28) Casida, M. E.; Jamorski, C.; Casida, K. C.; Salahub, D. R. Molecular excitation energies to high-lying bound states from timedependent density-functional response theory: characterization and correction of the time-dependent local density approximation ionization threshold. J. Chem. Phys. 1998, 108 (11), 4439-4449.

(29) Because the accuracy of the method depends on the exchangecorrelation functional used, TD-DFT may not provide exact transition energies. As is now well-known, the exchange-correlation functionals work very well for ground states and for low-lying valence excited states. However, for high-lying diffuse excited states TD-DFT employing conventional functionals may be less reliable, and the excitation energies can be substantially underestimated. This is because the exchange-correlation potentials generated from these functionals decay rapidly (exponentially) rather than the gradual $(1 / r)$ asymptotic decay of the true potential. 